\title{
SHARP BOUNDS FOR TOADER-QI MEAN IN TERMS OF LOGARITHMIC AND IDENTRIC MEANS
}

\author{
Zhen-Hang Yang, Yu-Ming Chu And Ying-Qing Song
}

Abstract. In the article, we prove that the double inequality $\lambda \sqrt{L(a, b) I(a, b)}<T Q(a, b)<$ $\mu \sqrt{L(a, b) I(a, b)}$ holds for all $a, b>0$ with $a \neq b$ if and only if $\lambda \leqslant \sqrt{e / \pi}$ and $\mu \geqslant 1$, and give an affirmative answer to the conjecture proposed by Yang in [39], where $L(a, b)=$ $(b-a) /(\log b-\log a), I(a, b)=\left(b^{b} / a^{a}\right)^{1 /(b-a)} / e$ and $T Q(a, b)=\frac{2}{\pi} \int_{0}^{\pi / 2} a^{\cos ^{2} \theta} b^{\sin ^{2} \theta} d \theta$ are respectively the logarithmic, identric and Toader-Qi means of $a$ and $b$.

Mathematics subject classification (2010): 26E60, 33C10.

Keywords and phrases: Toader-Qi mean, logarithmic mean, identric mean, modified Bessel function.

\section{REFERENCES}

[1] M. Abramowitz And I. A. STEgun, Handbook of Mathematical Functions with Formulas, Graphs, and Mathematical Tables, U. S. Government Printing Office, Washington, 1964.

[2] H. ALZER, Ungleichungen für Mittelwerte, Arch. Math. 47, 5 (1986), 422-426.

[3] M. BIERNACKI AND J. KRZYŻ, On the monotonity of certain functionals in the theory of analytic functions, Ann. Univ. Mariae Curie-Skłodowska, Sect. A 9 (1955), 135-147.

[4] B. C. CARLson, Algorthms involving arithmetic and geometric means, Amer. Math. Monthly 78 (1971), 496-505.

[5] B. C. CARLSON, The logarithmic mean, Amer. Math. Monthly 79 (1972), 615-618.

[6] B. C. CARLSON AND J. L. Gustafson, Total positivity of mean values and hypergeometric functions, SIAM J. Math. Anal. 14, 2 (1983), 389-395.

[7] Y.-M. ChU, S.-W. Hou AND W.-F. XIA, Optimal convex combinations bounds of centroidal and harmonic means for logarithmic and identric means, Bull. Iranian Math. Soc. 39, 2 (2013), 259-269.

[8] Y.-M. ChU AND B.-Y. Long, Bounds of the Neuman-Sándor mean using power and identric means, Abstr. Appl. Anal. 2013, Article ID 832591 (2013), 6 pages.

[9] Y.-M. ChU, M.-K. WANG, Y.-F. QIU AND X.-Y. MA, Sharp two parameter bounds for the logarithmic mean and the arithmetic-geometric mean of Gauss, J. Math. Inequal. 7, 3 (2013), 349-355.

[10] Y.-M. ChU, M.-K. WANG AND Z.-K. WANG, A sharp double inequality between harmonic and identric means, Abstr. Appl. Anal. 2011, Article ID 657935 (2011), 7 pages.

[11] Y.-M. CHU, M.-K. WANG AND Z.-K. WANG, Best possible inequalities among harmonic, geometric, logarithmic and Seiffert means, Math. Inequal. Appl. 15, 2 (2012), 415-422.

[12] Y.-M. CHU AND W.-F. XIA, Two optimal double inequalities between power mean and logarithmic mean, Comput. Math. Appl. 60, 1 (2010), 83-89.

[13] P. Kahlig and J. Matkowski, Functional equations involving the logarithmic mean, Z. Angew. Math. Mech. 76, 7 (1996), 385-390.

[14] T. P. LiN, The power mean and the logarithmic mean, Amer. Math. Monthly 81 (1974), 879-883.

[15] A. O. Pittenger, Inequalities between arithmetic and logarithmic means, Univ. Beograd. Publ. Elektrotehn. Fak. Ser. Mat. Fiz. 678-715, 1980, 15-18.

[16] A. O. Pittenger, The symmetric, logarithmic and power means, Univ. Beograd. Publ. Elektrotehn. Fak. Ser. Mat. Fiz. 678-715 (1980), 19-23.

[17] A. O. Pittenger, The logarithmic mean in $n$ variables, Amer. Math. Monthly 92, 2 (1985), 99-104. 
[18] G. Pólya AND G. Szegö, Isoperimetric Inequalities in Mathematical Physics, Princeton University Press, Princeton, 1951.

[19] G. Pólya AND G. Szegö, Problems and Theorems in Analysis I, Springer-Verlag, Berlin, 1998.

[20] F. QI, Bounds for the ratio of two gamma functions, J. Inequal. Appl. 2010, Article ID 493058 (2010), 84 pages.

[21] F. QI, X.-T. SHI, F.-F. LIU AND ZH.-H. YANG, A double inequality for an integral mean in terms of the exponential and logarithmic means, DOI: 10.13140/RG.2.1.2353.6800, available online at http://www.researchgate.net/publication/278968439.

[22] Y.-F. QIU, M.-K. WANG, Y.-M. ChU AND G.-D. WANG, Two sharp inequalities for Lehmer mean, identric mean and logarithmic mean, J. Math. Inequal. 5, 3 (2011), 301-306.

[23] J. SÁNDOR, On the identric and logarithmic means, Aequationes Math. 40, 2-3 (1990), 261-270.

[24] J. SÁNDOR, A note on some inequalities for means, Arch. Math. 56, 5 (1991), 471-473.

[25] J. SÁNDOR, On certain identities for means, Studia Univ. Babeş-Bolyai Math. 38, 4 (1993), 7-14.

[26] J. SÁNDOR, On certain inequalities for means, J. Math. Anal. Appl. 189, 2 (1995), 602-606.

[27] J. SÁNDOR, On certain inequalities for means II, J. Math. Anal. Appl. 199, 2 (1996), 629-635.

[28] J. SÁNDOR AND I. RAŞA, Inequalities for certain means in two arguments, Nieuw Arch. Wisk.(4) 15, 1-2 (1997), 51-55.

[29] H.-J. SEIFFERT, Ungleichungen für elementare Mittelwerte, Arch. Math. 64, 2 (1995), 129-131.

[30] K. B. Stolars Ky, Generalizations of the logarithmic mean, Math. Mag. 48 (1975), 87-92.

[31] K. B. Stolarsky, The power and generalized logarithmic means, Amer. Math. Monthly 87, 7 (1980), 545-548.

[32] GH. TOAder, Some mean values related to the arithmetic-geometric mean, J. Math. Anal. Appl. 218, 2 (1998), 358-368.

[33] M. K. Vamanammurthy and M. Vuorinen, Inequalitie for means, J. Math. Anal. Appl. 183, 1 (1994), 155-166.

[34] M.-K. WANG, Y.-M. ChU AND Y.-F. QIU, Some comparison inequalities for generalized Muirhead and identric means, J. Inequal. Appl. 2010, Article ID 295620 (2010), 10 pages.

[35] M.-K. WANG, Z.-K. WANG AND Y.-M. ChU, An optimal double inequality between geometric and identric means, Appl. Math. Lett. 25, 3 (2012), 471-475.

[36] ZH.-H. YANG, On the homogeneous functions with two parameters and its monotonicity, JIPAM. J. Inequal. Pure Appl. Math. 6, 4 (2005), Article 101, 11 pages.

[37] ZH.-H. YANG, On the log-convexity of two-parameter homogeneous functions, Math. Inequal. Appl. 10, 3 (2007), 499-516.

[38] ZH.-H. YANG, The log-convexity of another class of one-parameter means and its applications, Bull. Korean Math. Soc. 49, 1 (2012), 33-47.

[39] ZH.-H. YANG, New sharp bounds for logarithmic mean and identric mean, J. Inequal. Appl. 2013 (2013), Article 116, 17 pages.

[40] ZH.-H. YANG, Some sharp inequalities for the Toader-Qi mean, arXiv:1507.05430 [math.CA], available online at http://lib-arxiv-008. serverfarm.cornell.edu/abs/1507.05430.

[41] ZH.-H. YANG AND Y.-M. CHU, An optimal inequalities chain for bivariate means, J. Math. Inequal. 9, 2 (2015), 331-343.

[42] T. Zhang, W.-F. XIA, Y.-M. ChU And G.-D. WANG, Optimal bounds for logarithmic and identric means in terms of generalized centroidal mean, J. Appl. Anal. 19, 1 (2013), 141-152. 